\title{
Children's Attributions in the Family: The Children's Relationship Attribution Measure
}

\author{
Frank D. Fincham \\ University of Wales, Cardiff
}

\author{
Steven R. H. Beach, Ileana Arias, and \\ Gene H. Brody \\ University of Georgia
}

\begin{abstract}
This study assessed children's attributions in parent-child relationships, examined their association with relationship positivity and behavior displayed toward the parent, determined whether depressive symptoms account for these associations, and investigated whether parent and child attributions are linked. Ten- to 12-yearold children (116 girls, 116 boys) completed several questionnaires and were observed during parent-child interactions. Children's attributions for parent behavior were related to positivity of the parent-child relationship and to self- and parent-reported conflict and observed behavior with the father. These associations were not due to children's depressive symptoms but potentially augment our understanding of the effect of depression on parent-child relationships. Finally, gender moderated the parent attribution-child attribution association. The results underscore the importance of children's perceptions of family processes.
\end{abstract}

The study of children's perceptions of family events has led to increased understanding of their reactions to such events at both theoretical (e.g., Davies \& Cummings, 1994; Grych \& Fincham, 1990) and empirical levels (e.g., Grych, Seid, \& Fincham, 1992; Kurdek \& Berg, 1987; Mazur, Wolchik, \& Sandler, 1992). Although children's attributions or explanations for events predict their functioning in several

Frank D. Fincham, School of Psychology, University of Wales, Cardiff, Great Britain; Steven R. H. Beach and Ileana Arias, Department of Psychology, University of Georgia; Gene H. Brody, Department of Child and Family Development, University of Georgia.

This study was supported by National Institute on Alcohol Abuse and Alcoholism Grant AA09224, by a grant from the Economic and Social Research Council, and by a Social Science Research Fellowship from the Nuffield Foundation awarded to Frank D. Fincham.

Correspondence concerning this article should be addressed to Frank D. Fincham, School of Psychology, P.O. Box 901, University of Wales, Cardiff, Cardiff CF1 3YG Great Britain or to Gene H. Brody, Department of Child and Family Development, Dawson Hall, University of Georgia, Athens, Georgia 30602. Electronic mail may be sent to Frank D. Fincham at fincham@cf.ac.uk or to Gene H. Brody at gbrody@uga.cc.uga.edu. domains (e.g., reactions to peer behavior, Crick \& Dodge, 1994; manifestation of depressive symptoms, Gladstone \& Kaslow, 1995), a body of knowledge has not yet emerged on children's attributions in family relationships. This omission is further underscored by numerous studies on adults' attributions for relationship events that have advanced understanding of marriage (see Fincham, 1994) and parent-child relationships (see Miller, 1995). The present study, therefore, focused on children's attributions in the context of the parent-child relationship and investigated theoretically predicted associations with the positivity of the parent-child relationship and with reported and observed behavior. In doing so, it tested whether the hypothesized correlates of children's attributions are an artifact of depressive symptoms. Finally, it examined the relationship between parental and child attributions.

At a theoretical level, it can be hypothesized that attributions are important for understanding children's relationships to their parents for two main reasons. First, in developing attribution theory, Heider (1958) argued that the nature of the attributions a person makes should be related to whether the person likes the attribution target. This hypothesized link between attributions and relationship positivity has led to the hypothesis 
that attributions can change, maintain the quality of the relationship between the attributor and the attribution target, or both. Second, Heider noted that the attribution made for a person's behavior is likely to influence the attributor's behavior toward the attribution target. In research on close relationships, this factor has led to the hypothesis that attributions made for an intimate's behavior will be related to behavior shown in interactions with him or her.

There is evidence from studies of adults to support each of these hypotheses for negative relationship events (i.e., the events that prompt attribution processing, Weiner, 1985). First, attributions for spouse behavior are related to current marital satisfaction and predict future marital satisfaction (e.g., Fincham \& Bradbury, 1991; Fincham, Bradbury, Arias, Byrne, \& Karney, 1997). Second, attributions are related to observed behavior during laboratory interactions (e.g., Bradbury, Beach, Fincham, \& Nelson, 1996; Bradbury \& Fincham, 1992; for reviews, see Bradbury \& Fincham, 1990; Fincham, 1998). In particular, attributions for negative behavior that show certain features (infer the behavior is intentional, selfishly motivated, and blameworthy; locate the cause of the behavior in the partner; and view the cause as global and stable) accentuate the impact of negative partner behavior. Such attributions can be characterized as conflict-promoting attributions and are associated with relatively more negative behavior toward the partner. Accordingly, in adulthood, attributions are related in important ways to relationship satisfaction and behavior.

Is there similar evidence linking children's attributions to their behavior and the nature of their relationships? As regards child behavior, there is evidence to show that the tendency to infer hostile intent for hypothetical, ambiguous peer behaviors predicts retaliatory aggressive responses, later acts of aggression, and teacher ratings of reactive aggression (e.g., Crick \& Dodge, 1996; Dodge, Bates, \& Pettit, 1990). However, assessment of children's attributions in this domain has examined only hostile intent. A limitation of this assessment is that it focuses on one of several possible dimensions of responsibility attributions (which concern accountability for an event) relevant to understanding interpersonal behavior and does not assess dimensions underlying causal attributions (which concern who or what produced an event; see Fincham \& Jaspars, 1980; Shaver, 1985). As regards children's relationships, Cook (1993) developed a multidimensional measure of locus of control with college students and extended its use to other family members, including siblings of 12 years or older. He found that beliefs about interpersonal control in the family reflected characteristics of the family member to whom the beliefs pertained, the relationship with the family member, and the characteristics of the perceiver. This study emphasizes the need to study children's attributions for each parent separately, but again, the data pertain to a single attribution dimension (locus).

In contrast, the attribution measures used in research on children's depressive symptoms, the Children's Attribution Styles Questionnaire (CASQ; Seligman et al., 1984) and CASQRevised (Kaslow \& Nolen-Hoeksema, 1991), assess three dimensions underlying causal attributions (locus, stability, and globality). Metaanalyses show that internal, stable, and global attributions for negative events and external, unstable, and specific attributions for positive events are associated with concurrent depressive symptoms and that a combined index for positive and negative events predicts future depressive symptoms (Gladstone \& Kaslow, 1995; Joiner \& Wagner, 1995). Although the original and revised CASQs include attributions for interpersonal events, these attributions tend not to be analyzed independently of attributions for achievement events (for an exception, see Turner \& Cole, 1994). Moreover, even if interpersonal events were analyzed separately, they would provide information only about attributions the child makes for his or her own interpersonal behavior rather than the behavior of a significant other. Thus, there is evidence that by early adolescence attributions are consequential for affective reactions and for some aspects of interpersonal behavior. However, evidence regarding the role of child and adolescent attributions in family relationships is scant.

In view of these observations, there is a need for the development of an attribution measure that assesses multiple dimensions of children's attributions in interpersonal contexts, particularly the family. This task can be facilitated by drawing on marital attribution research. Utiliz- 
ing this resource yields three important advantages. First, marital researchers have identified the responsibility attribution dimensions (inferred intent, motivation, blame) and causal attribution dimensions (locus, stability, globality) that are useful for understanding relationships. Second, use of marital attribution assessment procedures could result in analogous attribution measures in marital and parent-child relationships. Third, the marital literature provides a theoretical analysis of attributions in close relationships (see Bradbury \& Fincham, 1990) that can be used to establish the validity of a child attribution measure and to inform research on children.

It is therefore perhaps not surprising that Grace, Kelley, and McCain (1993) adapted a marital attribution measure, the Marital Attribution Style Questionnaire (Fincham, Beach, \& Nelson, 1987), to show that adolescents' conflictpromoting attributions for maternal behaviors were positively related to reported conflict between mother and child. However, this adaptation is limited in several ways. First, little attention was given to establishing the psychometric properties of the measure. Second, fathers were not studied, and there is growing empirical evidence that findings pertaining to mother-child relations cannot be generalized to father-child relations (e.g., Osborne \& Fincham, 1996; Phares \& Compas, 1992). Third, the results are not examined in relation to child gender. Fourth, only self-report measures of behavior were used, thereby providing limited data on which to evaluate the validity of the measure. Finally, except for the target events for which attributions were made, the format of the attribution assessment was identical to that used in an early marital attribution measure, which is important because limitations of the measure led to its revision. Specifically, the format of the measure was changed to make the attribution assessment simpler and to avoid ambiguities in interpretation of responses (see Fincham \& Bradbury, 1992).

The present study addressed each of these limitations by examining children's attributions for mothers' and fathers' behavior in relation to both self-reported, parent-reported, and observed behavior with each parent. It was hypothesized that attributions accentuating the impact of negative parent behavior (conflictpromoting attributions) would be positively related to reports of maladaptive conflict interactions and inversely related to the positivity of behavior observed in parent-child interaction.

An important feature of research on attributions in marital relationships has been the attention paid to ruling out competing hypotheses for hypothesized associations (Fincham, 1994). One competing hypothesis is that depressive symptoms influence both attributions and relationships. Is this hypothesis relevant when investigating children's attributions? Two factors suggest that children's depressive symptoms should be considered when examining their attributions. First, as noted earlier, there is a well-documented relation between children's attributions and depressive symptoms (Gladstone \& Kaslow, 1995; Joiner \& Wagner, 1995). Finding an association between children's attributions for parent behavior and depressive symptoms is therefore important as it would document an additional theoretically expected correlate of children's attributions. However, the existence of any such association between attributions and depressive symptoms raises the possibility that other associations found for children's attributions may simply be an artifact of depressive symptoms. It is therefore important to rule out such an artifactual explanation for any attribution findings.

Second, childhood depression is itself related to family processes, including impairment of the parent-child relationship (see Kaslow, Deering, \& Racusin, 1994). To the extent that depressive symptoms are associated with the parent-child variables investigated in this study, and presuming that they do not account for associations involving attributions, an interesting question arises. What is the relative contribution of attributions and depressive symptoms in accounting for variance in parent-child relationship variables?

Finally, the study of children's attributions raises the question of their origin. Although not the primary focus of the present study, we examined one mechanism that might account for the acquisition of attributions in children. Children might acquire the tendency to make particular types of attributions through modeling the attributions displayed by a parent. According to this hypothesis, there should be a positive correlation between the attributions made by a parent and a child. Seligman et al. (1984) found some support for this hypothesis in 
that mothers' attributions for bad events correlated with their children's attributions. Fathers' attributions were unrelated to those of the mothers or the children. In a similar vein, Fincham and Cain (1986) found significant correlations between mothers' and fathers' attributions for their third graders' failures on academic tasks and their children's attributions for the failure.

As can be seen, data on the origins of children's attributions in the family are rare and tend to focus on achievement contexts where attributions are made for one's own behavior. In interpersonal contexts, however, attributions are often made for another person's behavior. Differences between attributions for self and other preclude generalization of the above findings in the absence of their replication in interpersonal contexts. Moreover, because it is possible that children are more likely to model the same-gender parent and to respond to interparental aggression differently as a function of parent gender and own gender (e.g., Davis, Hops, Alpert, \& Sheeber, 1998), it is important to examine gender as a possible moderator of any relationship found between parent and child attributions. The need to examine the interaction between parent and child gender is underscored by the fact that it has received limited attention despite widespread theoretical and empirical interest in the role of gender in understanding parent-child relationships (for a review, see Russell \& Saebel, 1997).

In sum, there is a need for a short, reliable measure that uses a simple format to assess children's attributions in the family. Accordingly, this study drew on marital attribution research in developing the Children's Relationship Attribution Measure (CRAM) to assess children's attributions for parental behaviors.

\section{Method \\ Participants}

As a goal of the study was to develop a self-report, attribution questionnaire, it was important to select children at an age where they can adequately respond to written materials. This consideration, together with the fact that the attribution ratings required children to be willing to consider seeing parental behavior as selfishly motivated and blameworthy, led us to investigate children as they began to make the transition to adolescence and to establish a greater sense of self.

Two hundred and thirty two families that included married parents and a 10- to 12-year-old biological child of both parents (116 girls, $M=11.92$, $S D=0.59 ; 116$ boys, $M=11.98, S D=0.58$ ) were recruited from 12 nonmetropolitan counties in Georgia in which community populations range from several hundred to 15,000 persons. We recruited families by using a telephone-directory-based random sampling strategy to contact households that included at least one child between the ages of 10 and 15 years. Although approximately $88 \%$ of all Georgia households, and over $90 \%$ of adult Georgia residents, can be contacted by phone, it is important to note that persons with unlisted numbers, or those who do not have a phone, were automatically excluded from participation in the study. Letters were sent to these households to acquaint the families with the purposes of the study and to inform them that they would be contacted by a staff member to determine their willingness to participate. Of the eligible families, $71 \%$ agreed to participate in the study. Seventy-seven percent of the families were Caucasian, and $23 \%$ were African American. The modal level of education attained by both fathers and mothers was some college or trade school (but no degree) with education ranging from fourth grade to a doctorate or professional degree (for further demographic information, see Table 1).

Table 1

Demographic Characteristics of Sample

\begin{tabular}{lrcc}
\hline \multicolumn{1}{c}{ Variable } & $M$ & \multicolumn{1}{c}{$S D$} & Range \\
\hline Husband age (years) & 41.28 & 5.59 & $30-70$ \\
Wife age (years) & 38.59 & 4.60 & $28-50$ \\
No. of children & 2.44 & 0.99 & $1-8$ \\
Family income $(\$$, yearly) & 52,507 & 30,994 & $2,160-263,400$ \\
Per capita income (\$, yearly) & 11,834 & 7,148 & $360-52,680$ \\
Wife income (\$, yearly) & 17,987 & 12,693 & $781-86,400$ \\
Husband income (\$, yearly) & 38,040 & 28,616 & $4,800-260,400$ \\
\hline
\end{tabular}




\section{Procedure}

Families were visited by two research assistants on two occasions approximately 1 week apart. During the initial home visit, parent and child consent was obtained for participation in the study, and the target child was videotaped while participating in two dyadic interactions, one with the mother and one with the father, with the onder of the interactions counterbalanced across the sample. The interactions were structured around a task (cf. Conger et al., 1992) in which each parent-child dyad was given a set of cards on which were printed questions that they were to discuss about parenting practices, schoolwork, household chores, and other important family events that can give rise to conflict between parent and child. The researcher explained the procedures to each dyad and had them complete a practice card, then went to another part of the house where he or she could not hear the parent-child interactions. Each interaction lasted $15 \mathrm{~min}$.

Questionnaires were administered on a laptop computer during both visits to each parent and child, privately with no other family members present. Items were presented one at a time on the computer screen, and respondents entered their response selections on keypads with large numerals. A cardboard partition prevented the research assistant from seeing any respondent's answers.

\section{Measures}

\section{Children's Attributions}

Children's attributions for each parent's behavior were assessed with the CRAM. Informed by and patterned after the Relationship Attribution Measure (RAM: Fincham \& Bradbury, 1992), the CRAM focuses on negative parental behavior. Negative events were used because (a) they are more likely to elicit attributions, (b) attributions for them are more reliably related to relationship quality than are attributions for positive events (Bradbury \& Fincham, 1990), and (c) they are most relevant in clinical contexts. The two stimulus behaviors ("Imagine your dad [mom] yelled at you," "Imagine your dad [mom] criticized you") included in the CRAM were adapted from the RAM and were selected because they are common enough to permit virtually all children to imagine their parents engaging in them.

For each parental behavior, children rated their agreement with six attribution statements. Three statements pertained to causal attribution dimensions: locus ("My father's [mother's] behavior was due to something about him [her]-because he [she] was tired, or because he [she] was in a bad mood, or because that's the way he (she] is"), stability ("Do you think that your dad [mom] will criticize you for the same reason the next time he [she] criticizes you?"), and globality ("Do you think that the reason your dad [mom] criticizes you affects other things that he [she] says or does to you, or other things that happen between the two of you?"). The remaining three statements pertained to responsibility attributions: intentionality ("Do you think your mom [dad] criticized you on purpose to hurt your feelings?"), motivation ("Do you think that your mom [dad] was thinking only about herself [himself] when she [he] criticized you?"), and blame ("Do you think that your dad [mom] should be blamed for criticizing you?"). On the 6-point rating scale, each point, ranging from disagree strongly to agree strongly, was labeled to make the task as concrete as possible. For each parent, responses to corresponding attribution statements were summed across the stimulus behaviors, yielding a single score for each attribution dimension. Higher scores indicated more conflictpromoting attributions.

\section{Relationship Positivity}

The Positive Affect Index (PAI; Bengston \& Schrader, 1982) was used to assess positive feelings between parent and child. The child, mother, and father each completed the PAI. The PAI was chosen over other measures of relationship quality because it was specifically designed to assess positive affect between generations. The respondent reports the amount of positive affect that he or she has for another person and the positive affect that he or she perceives another person has toward him or her. In this study, we used only the respondent's reports of his or her own affect as we wanted to avoid results that simply reflected associations between two measures that included children's inferences about the parent or parents' inferences about their children. The respondent indicated the extent to which positive features (e.g., trust, understanding, love) characterized the parent-child relationship and responded to items (e.g., "How much love do you have toward your father (mother, child]?") using a 6-point scale ranging from not much to very, very much. To make the scale as concrete as possible, each point on it was labeled. Scores were summed on this five-item index, which ranged from 5 to 30 , with higher scores indicating more positivity. Coefficient alpha for this measure was high (coefficient alpha for child reports, father $=.93$, mother $=.94$; for maternal report $=.87$; for paternal report $=.89$ ). 


\section{Depressive Symptoms}

We assessed depressive symptoms by using the Center for Epidemiologic Studies Depression Scale (CES-D; Radloff, 1977). The CES-D uses items that are rated on a 4-point Likert-type scale indicating how often in the last week the respondent experienced various depressive symptoms (e.g., "How often did you feel like not eating; had a poor appetite?" "How often did you feel that everything you did was an effort?"). Children's responses were summed across items, with higher scores indicating more depressive symptoms (coefficient alpha, boys $=.74$, girls $=.80$ ).

\section{Behavior}

Reports. The child and each parent completed the Ineffective Arguing Inventory (IAI; Kurdek, 1994). This measure is based on the concept that ineffective arguing is a global, unidimensional interaction pattern that includes repetitive fighting over the same issues, knowing how an argument is going to end even before it is over, ending the argument without resolving the issue at hand, and ending the argument with neither partner feeling that he or she was given a fair hearing. For young adolescents, chronic enactment of the ineffective arguing pattern that the IAI indexes has been shown to promote more disengaged and hostile family relationships, as well as higher levels of externalizing and internalizing problems in the youths (Conger et al., 1992). The respondent indicated the extent to which scale items (e.g., "Our arguments are left hanging and unresolved") reflected the way in which parent-child arguments were handled (coefficient alpha for child reports, father $=.76$, mother $=.65$; for maternal report $=.77$; for paternal report $=.74$ ).

Observed behavior. Parent-child interactions were rated with a 5-point Likert scale, on which 1 indicated that the behavior under consideration never occurred and 5 indicated that the behavior was mainly characteristic of the participant's interaction, occurring frequently or consistently. Ratings therefore reflected the overall judgment of raters regarding the interaction. Raters received $30 \mathrm{hr}$ of training before rating videotapes.

A measure of positive child behavior was obtained with ratings of the child's general positivity toward the parent (expression of affection, concern, or appreciation; showing empathy, acceptance, or interest in the parent; use of positive affect) and of positive communication (explaining, reasoning, or expressing interest in the parent's views; facilitating the discussion). Reliability was calculated with split-half Spearman-Brown coefficients, computed for each possible pair of observers. Reliability between raters was .82 for general positivity and .84 for positive communication. Scores for the two indexes were summed to form a positive behavior score.
An observational measure of negative child behavior was formed with two rating scales. The Criticism scale indicated the extent to which the child made accusations of untrustworthiness against the parent and made numerous and generalized complaints about the parent. The Negative Affect scale included frowning, scowling, using an irritable or curt tone of voice, and negative touching such as hitting or shoving. Reliability was .86 for the Criticism scale and .82 for the Negative Affect scale. The two indexes were summed to form a negative interaction score.

Because it is the relative balance between positive and negative behaviors that appears to be critical for understanding relationships (Gottman, 1994), we formed an overall index of child behavior with each parent by subtracting the negative index from the positive index. Higher scores on this index reflected relatively more positive behavior. ${ }^{1}$

Parent attributions for spouse behavior. Parent attributions were assessed with an 18-item version of the RAM (Fincham \& Bradbury, 1992). Spouses were asked to rate, on a 6-point scale, the extent to which they agreed or disagreed with six attribution statements made about each of three negative partner behaviors ("Your husband/wife begins to spend less time with you," "Your husband/wife is cool and distant," and "Your husband/wife does not pay attention to what you are saying"). Three statements pertained to causal attributions (locus, globality, and stability), and three pertained to responsibility attributions (intent, selfish motivation, and blame). To obtain an index of attributions analogous to that used for children, responses were summed across attributions and across stimulus behaviors, with higher scores reflecting more conflict-promoting attributions (coefficient alpha, husbands $=.94$, wives $=.94$ ) .

\section{Results}

Table 2 shows the means and standard deviations for the child-related variables investigated. The analyses pertaining to the data are presented in terms of the four issues addressed, namely, the assessment of children's attributions, their association with relationship positivity and conflict behavior, the role of depressive symptoms in accounting for associations involving attributions, and the link between parental and child attributions. Analyses were conducted on the sample of 219 families (114 boys, 115 girls) for which complete data were available on all the measures.

\footnotetext{
1 The same results were obtained when ratings of positive behavior and of negative behavior were examined separately.
} 


\section{Assessing Children'Attributions}

The CRAM included assessment of several attribution dimensions. Principal components analyses were used to determine the number of dimensions that might underlie children's attribution responses (using an eigenvalue greater than 1 as a criterion). Attributions for each parent yielded a single principal component with all attribution dimensions loading .6 or above on the component (see Table 3). The reliability of the unidimensional scales yielded by the principal-components analyses were assessed by computing coefficient alphas. The scale yielded good internal consistency (fathers $=.80$, mothers $=.76$ ) with alpha coefficients exceeding the lower level $(.70)$ recommended for research use (Nunally \& Bernstein, 1994).

In view of these findings, a single attribution index was formed relating to attributions for each parent's behavior by summing across each attribution dimension. Higher scores on this index indicated greater conflict-promoting attri-

Table 2

Means and Standard Deviations for Measures

\begin{tabular}{lrr}
\hline \multicolumn{1}{c}{ Measure } & $M$ & $S D$ \\
\hline \multicolumn{2}{c}{ Child report } \\
Attributions & 26.51 & 8.78 \\
$\quad$ Father & 24.06 & 7.80 \\
$\quad$ Mother & 16.89 & 5.10 \\
Ineffective arguing & 16.96 & 4.46 \\
$\quad$ Father & & \\
$\quad$ Mother & 5.20 & 0.80 \\
Relationship positivity & 5.39 & 0.73 \\
$\quad$ Father & 14.13 & 8.25 \\
$\quad$ Mother &
\end{tabular}

Parent report

\begin{tabular}{|c|c|c|}
\hline \multicolumn{3}{|c|}{ Ineffective arguing } \\
\hline Father & 15.58 & 3.95 \\
\hline Mother & 15.64 & 4.01 \\
\hline \multicolumn{3}{|c|}{ Relationship positivity } \\
\hline Father & 5.26 & 0.50 \\
\hline Mother & 5.25 & 0.48 \\
\hline \multicolumn{3}{|c|}{ Spouse attributions } \\
\hline Husband & 70.68 & 19.24 \\
\hline Wife & 72.47 & 20.28 \\
\hline \multicolumn{3}{|c|}{ Observed interaction } \\
\hline Father-child & 4.25 & 1.88 \\
\hline Mother-child & 3.61 & 1.85 \\
\hline
\end{tabular}

Table 3

Factor Loadings of Child Attribution Dimensions

\begin{tabular}{lrr}
\hline $\begin{array}{l}\text { Attribution } \\
\text { dimension }\end{array}$ & Father & Mother \\
\hline Locus & .71 & .68 \\
Globality & .75 & .71 \\
Stability & .65 & .63 \\
Intent & .73 & .69 \\
Motivation & .74 & .67 \\
Blame & .68 & .70 \\
$\quad$ Eigenvalue & 3.05 & 2.79 \\
\% of variance & 51 & 47 \\
\hline
\end{tabular}

butions. Although these findings suggest that consistent attribution responses for parental behavior can be obtained from early adolescents, they do not speak to the validity of these responses, a topic to which we now turn.

\section{Attributions, Relationship Positivity, and Conflict Behavior}

To examine whether attributions were related to the quality of the parent-child relationship, Pearson correlations were computed between the attribution index for each parent and the extent to which the child viewed the relationship as positive. Consistent with attribution theory and findings in the marital literature, children's attributions correlated significantly with the positivity of the father-child and mother-child relationships experienced by the child; conflictpromoting attributions were inversely correlated with child-reported relationship positivity (see Table 4). Interestingly, the associations found from child reports of the relationship were consistent with those obtained for father reports of relationship positivity.

Table 4 also shows the correlations pertaining to the hypothesized association between attributions and behavior. As regards reported conflict behavior, children's reports of conflict that reflect the use of ineffective arguing patterns were positively related to conflict-promoting attributions for paternal and maternal behavior, which confirms theoretical predictions. Parental reports of conflict behavior were also related to children's attributions for both fathers and mothers. Although not specifically predicted by attribution theory, the association found between child-reported attributions and parent- 
Table 4

Correlations Between Child Confict-Promoting Attributions and Perceived Positivity of

Parent-Child Relationship, Reports of Arguing, and Parent-Child Interaction

\begin{tabular}{lrr}
\hline & \multicolumn{2}{c}{ Child attributions } \\
\cline { 2 - 3 } Measure & Father & Mother \\
\hline Child report & & \\
$\quad$ Relationship positivity & $-.33^{* *}$ & $-.30^{* *}$ \\
$\quad$ Arguing & $.38^{* *}$ & $.20^{* *}$ \\
Parent report & & \\
$\quad$ Relationship positivity & $-.24^{* *}$ & -.03 \\
$\quad$ Arguing & $.16^{* *}$ & $.16^{* *}$ \\
Observed interaction & $-.25^{* *}$ & -.09 \\
\hline
\end{tabular}

${ }^{* *} p<.01$.

reported conflict behavior suggests that the attribution-conflict behavior association is robust and not limited to data obtained from the same source.

The correlations obtained for observed behavior further support the view, at least for fathers, that the association found between attributions and ineffective arguing does not simply reflect a reporting bias. The index of child behavior computed from the responses of trained coders correlated with children's attributions for father behavior. Thus, the same pattern of associations was found between attributions and behavior toward fathers with observational as well as self-report measures of behavior. No relationship was found between child attributions for mother behavior and behavior toward the mother.

\section{Depressive Symptoms, Attributions, and Parent-Child Relations}

It can be argued that attributions are related to relationship positivity and parent-child interaction variables only because these variables reflect the negativity associated with depressive symptomatology. Accordingly, we examined whether each of the variables correlated with depression.

As expected, children's attributions correlated significantly $(p<.05)$ with depressive symptoms (father $=.33$, mother $=.18$ ). Also as expected, depressive symptoms correlated $(p<.05)$ positively with ineffective arguing (for child report, fathers $=.39$, mothers $=.23$; for paternal report $=.28$; for maternal re- port $=.22$ ) and negatively with the positivity of the relationship with each parent (for child report, fathers $=-.30$, mothers $=-.16$; for paternal report $=-.26$; for maternal report $=-.16$ ). Interestingly, however, depressive symptoms did not correlate with observed child behavior toward either parent.

To examine whether the associations between attributions and parent-child variables were an artifact of depressive symptoms and to examine the relative contributions of attributions and depressive symptoms in accounting for variance in parent-child variables, we conducted several regression analyses. In each regression equation, attribution scores and depression scores were entered simultaneously into the regression to predict one of the parent-child variables investigated. This procedure was done separately for relationship positivity and for conflict behavior reported by children and by parents and for observed behavior, resulting in 10 regression equations.

Table 5 shows that, with one exception, the same pattern of findings emerged for attributions in these regression analyses as that found from simple bivariate correlations. The exception occurs for fathers' reports of ineffectual arguing. When children's depressive symptoms were statistically controlled, their attributions for father behavior were no longer significantly associated with fathers' reports of ineffectual arguing. Notwithstanding this exception, the associations found for attributions are not simply a function of depressive symptoms. In a similar vein, the same pattern of findings emerged for depressive symptoms in the bivariate correlational analyses and the regression analyses. Except for the association between depressive symptoms and child report of positivity of the mother-child relationship, statistically significant associations between depressive symptoms and the relationship were independent of the association between child attributions and the relationship variables.

\section{Parent Attributions and Child Attributions}

The attributions spouses made for each other's behavior were related $(p<.05)$ to children's attributions for father behavior (husband attributions $=.20$, wife attributions $=.27$ ) and for mother behavior (husband attributions $=.16$, wife attributions $=.13$ ). To examine the relative contribution of each spouse's 
Table 5

Prediction of Perceived Relationship Positivity, Reports of Arguing, and Parent-Child Interaction From Attribution and Depression Scores

\begin{tabular}{|c|c|c|c|c|c|c|}
\hline \multirow[b]{2}{*}{ Measure } & \multicolumn{3}{|c|}{ Fathers } & \multicolumn{3}{|c|}{ Mothers } \\
\hline & $R$ & $F(2,216)$ & $t(217)$ & $R$ & $F(2,216)$ & $t(217)$ \\
\hline CR: relationship positivity & .39 & $19.2^{* *}$ & & .32 & $12.1^{* *}$ & \\
\hline Attributions & & & $-3.9 * *$ & & & $-4.2^{* *}$ \\
\hline Depression & & & $-3.2 * *$ & & & -1.7 \\
\hline CR: arguing & .47 & $30.5 * *$ & & .28 & $9.4^{* *}$ & \\
\hline Attributions & & & $4.5^{* *}$ & & & $2.4^{*}$ \\
\hline Depression & & & $4.6 * *$ & & & $3.1 * *$ \\
\hline PR: arguing & .27 & $8.4^{* *}$ & & .25 & $7.2 * *$ & \\
\hline Attributions & & & 1.3 & & & $2.1^{*}$ \\
\hline Depression & & & $3.2^{* *}$ & & & $2.9 * *$ \\
\hline PR: relationship positivity & .32 & $12.0^{* *}$ & & .16 & $2.9 \dagger$ & \\
\hline Attributions & & & $-2.3^{*}$ & & & 0.04 \\
\hline Depression & & & $-3.3 * *$ & & & $-2.4^{*}$ \\
\hline Observed interaction & .26 & $6.1^{* *}$ & & .10 & $<1$ & \\
\hline Attributions & & & $-3.4 * *$ & & & -1.4 \\
\hline Depression & & & -0.04 & & & 0.2 \\
\hline
\end{tabular}

Note. $\mathrm{CR}=$ child report; $\mathrm{PR}=$ parent report.

$\dagger p<.06 . \quad *_{p}<.05 .{ }^{* *} p<.01$.

attributions to child attributions, we used husband attributions and wife attributions to predict child attributions for father behavior and for mother behavior, respectively. As modeling of parent attributions might be influenced by gender, the interaction between husband attributions for wife behavior and child gender and between wife attributions and child gender were also examined. The two interaction terms were entered into the regression equation after entering the main effects for each parent's attributions and child gender.

The regression equation predicting children's attribution for father behavior was significant, $R=.33, F(5,213)=7.59, p<.02$. However, the only significant predictor variable in the equation was that reflecting the interaction between husband attributions for wife behavior and child gender, $t(217)=1.98, p<.05$. To examine the nature of the interaction, we computed the correlation between father attributions for wife behavior and child attributions for father behavior for boys, $r(115)=.28, p<.01$, and girls, $r(114)=.11, p>.05$. Thus, husband attributions for wife behavior accounted for significant variance in child attributions over and beyond that of mother attributions, child gender, and their interaction only for boys.

The regression equation predicting child attributions for mother behavior was also significant, $R=.25, F(5,213)=2.73, p<.03$. In this equation, wife attributions for husband behavior were a significant predictor, $t(217)=$ $2.37, p<.02$. However, this main effect was qualified by its interaction with child gender, $t(217)=2.08, p<.03$. To examine the nature of this interaction, we computed the correlation between wife attributions for husband behavior and child attributions for mother behavior for boys, $r(115)=.00$, and girls, $r(114)=.27, p<$ .01 . Thus, wife attributions for husband behavior accounted for significant variance in child attributions for mother behavior over and beyond that of father attributions, child gender, and their interaction only for girls.

Overall, the findings regarding the relation between parent attributions for partner behavior and child attributions for parent behavior yielded an interesting, gender-related pattern of findings. Husband attributions for wife behavior were related to boys' attributions for their fathers' behavior, and wives' attributions for husband behavior were linked to girls' attributions for their mothers' behavior. This pattern is consistent with the modeling hypothesis but suggests that modeling may be most relevant in relation to same-sex parents and to children's attributions for that parent's behavior. 


\section{Discussion}

Examination of children's attributions in family relationships is timely and consistent with recent emphasis on children's perceptions in understanding their responses to family events (e.g., Davies \& Cummings, 1994; Grych \& Fincham, 1990). Just as attributional processes have proven to be important in understanding adult relationships, children's peer relationships, and depressive symptoms in children and adults, the present study examined whether attributional processes are also linked to children's feelings about, and behavior toward, their parents. It also examined the relation between spouse attributions for partner behavior and child attributions for parent behavior.

Fundamental to the examination of children's attributions in the family is evidence that they can be assessed reliably and that they relate to important aspects of children's relationships with their parents. Accordingly, a child attribution measure was developed that capitalized on the experience of marital researchers in constructing a simple, brief format for assessing attributions that yields an unambiguous attribution index. Although it incorporated numerous attribution dimensions, analysis of children's attributional responses on the CRAM yielded a single factor for both maternal and paternal behavior. The reliability of this unidimensional, attribution index was high and well above that recommended for research instruments. It thus appears that children may not distinguish between causal and responsibility attribution dimensions as has sometimes been found in the adult literature (e.g., Fincham \& Bradbury, 1992). An important question for future research therefore is to determine the developmental processes that lead to a distinction being drawn between perceptions of causal attributions, regarding who or what caused an event, and responsibility attributions that concern who is accountable or liable to sanction for the event.

Evidence relating to the validity of the CRAM was obtained in the context of examining two hypotheses derived from attribution theory, namely, that attributions are related to the nature of the relationship between the attributor and the attribution target and that attributions predict the attributor's behavior toward the attribution target. Support was found for both hypotheses. First, boys' and girls' conflict-promoting attributions for parental be- havior were inversely related to their perceived positivity of the relationship with the mother and with the father. Although attribution theory does not predict an association between a perceiver's attributions and the attribution target's experience of the relationship, parent reports of relationship positivity were also examined in relation to child attributions for parent behavior. Fathers' reports of relationship positivity were related to child attributions for father behavior. The absence of a relationship for mothers may reflect unconditional feelings about the child or it may reflect the fact that attributions play a different role in father-child and mother-child relationships, an issue to which we return in discussing the attributionbehavior association. The findings obtained for parent reports suggest that, at least for fathers, the association found between child attributions and the nature of the parent-child relationship is not due to use of a single source of data. Overall, the association documented between child attributions for parent behavior and the perceived positivity of the parent-child relationship is consistent with a substantial body of research on adults that has documented a robust association between attributions and marital satisfaction.

We investigated the second attribution hypothesis concerning the association between attributions and behavior using reports of conflict behavior and observed behavior between parent and child. Children's conflict-promoting attributions for parent behavior were related to their reports of conflict behavior with each parent and with each parent's report of conflict behavior with the child. These findings are particularly noteworthy as the measure of conflict behavior was not specific to the child's behavior but instead asked about behavior in the dyad, which presumably reflects the attributions of both parent and child. It is possible therefore that a child-specific measure of conflict behavior may have yielded higher associations than those reported.

As regards observed behavior, children's attributions were related to the way they interacted with their fathers. This finding is important because it shows that the association found between child attributions and behavior is not confined to measures collected using a single method. The absence of a relation between attributions for mother behavior and 
observed behavior toward the mother assumes particular importance in light of the fact that conflict-promoting attributions were related to children having less positive feelings toward the mother. It appears that children may not act on their attributions and behave more negatively toward their mothers, which might, in turn, account for the absence of an association between mothers' reports of relationship positivity and child attributions for mother behavior. One possible reason for not acting on attributions for mother behavior is that disrupted relations with the mother may be particularly threatening as adolescents tend to report having a closer and more supportive relationship with their mother than with their father (see Noller, 1994). In particular, support from the mother may be particularly important for girls as they begin to explore romantic relationships with boys.

In summary, the two hypotheses derived from attribution theory were supported in that child attributions for parent behavior were related to the nature of the parent-child relationship and to behavior. There was evidence that these findings do not reflect the use of data obtained from a single source, reliance on a single method of data collection, or reporter bias-a possibility one can investigate more fully by examining the role of depressive symptoms in accounting for the associations involving children's attributions.

As anticipated, CRAM scores were related to depressive symptoms, a finding consistent with the literature on attributions and childhood depression. This finding provides additional data on the validity of the CRAM as it documents a further theoretical correlate of children's attributions. At the same time, it also emphasizes the need to rule out depressive symptoms as a third variable accounting for associations involving CRAM scores. Thus, both attribution scores and extent of depressive symptoms were used conjointly to predict parent-child variables. Attributions continued to be associated with child- and father-reported relationship positivity, child- and motherreported arguing, and observed behavior in father-child interactions, even after controlling for depressive symptoms. Accordingly, with the exception of father-reported conflict behavior, the associations found for the CRAM cannot be attributed to children's depressive symptomatology.
Also as anticipated, depressive symptoms were related in every case to important family processes, including ineffective arguing with parents (as reported by child and each parent) and to child- and parent-reported positivity of the parent-child relationships. The multiple regression analyses used to rule out depressive symptoms as a confound in the relationship between attributions and family processes also address the question of whether depressive symptoms account for variance in these family processes that cannot be attributed to child attributions for parent behavior. Only in the case of child-reported positivity toward the mother did a previously significant association become nonsignificant. Thus, the contribution of attributions and depressive symptoms to these family processes tended to be independent.

An additional finding of interest is that attributions and depressive symptoms tended to account for more variance in father-child than mother-child relationships. This finding suggests that the factors influencing relationship positivity and perceived and observed interactional behavior with parents may be somewhat different for fathers and mothers. It is possible that the factors influencing interactions with fathers may be somewhat simpler than those governing interactions with mothers. Alternatively, it may be that fathers are more reactive to child state, child behavior, or both than are mothers, allowing child variables greater predictability of paternal compared with maternal relationship variables.

Finally, the documentation of theoretically meaningful associations for child attributions for parent behavior raises questions about the origins of children's attributions. One obvious means whereby children acquire attributions is through modeling of their parents, which implies an association between parent attributions and child attributions, an implication that was supported in this study. However, both identification processes and the greater likelihood of modeling others most similar to the self also suggest that gender may moderate the association between parent and child attributions. Evidence was obtained to support such a moderating effect; mother attributions for father behavior accounted for unique variance in girls' attributions for mother behavior, and father attributions for mother behavior accounted for unique variance in boys' attributions for father behavior. Thus, in the interpersonal context, 
gender may play a more important moderating role than in other contexts where a link between parent and child attributions has been documented (e.g., Fincham \& Cain, 1986; Seligman et al., 1984). Although the present study provides data consistent with a modeling hypothesis, the validity of this hypothesis awaits the collection of data that examine directly the mechanism linking parent and child attributions.

In summary, investigation of children's attributions for parental behavior provides a window on how children make sense of an important aspect of their interpersonal world. Because a number of theoretical positions bypothesize that the lessons learned about the interpersonal world through primary relationships with parents may generalize to later romantic relationships (e.g., attachment theory, object relations theory), investigation of children's attributions for parental behavior also holds considerable promise as a tool to investigate a range of theoretical positions. The present study not only represents an initial step in this direction but also provides a tool that can be used in future research.

\section{References}

Bengston, V. L., \& Schrader, S. S. (1982). Parentchild relations. In D. J. Mangen \& W. A. Peterson (Eds.), Research instruments in social gerontology, Vol 2. (pp. 115-185). Minneapolis: University of Minnesota Press.

Bradbury, T. N., Beach, S. R. H., Fincham, F. D., \& Nelson, G. M. (1996). Attributions and behavior in functional and dysfunctional marriages. Journal of Consulting and Clinical Psychology, 64, 569-576.

Bradbury, T. N., \& Fincham, F. D. (1990). Attributions in marriage: Review and critique. Psychological Bulletin, 107, 3-33.

Bradbury, T. N., \& Fincham, F. D. (1992). Attributions and behavior in marital interaction. Journal of Personality and Social Psychology, 63, 613-628.

Conger, R. D., Conger, K. J., Elder, G. H., Lorenz, F. O., Simons, R. L., \& Whitbeck, L. B. (1992). A family process model of economic hardship and adjustment of early adolescent boys. Child Development, 63, 526-541.

Cook, W. L. (1993). Interdependence and the interpersonal sense of control: An analysis of family relationships. Journal of Personality and Social Psychology, 64, 587-601.

Crick, N. R., Dodge, K. A. (1994). A review and reformulation of social information processing mechanisms in children's adjustment. Psychological Bulletin, 115, 74-101.
Crick, N. R., \& Dodge, K. A. (1996). Social information-processing mechanisms in reactive and proactive aggression. Child Development, 67, 9931002.

Davies, P. T., \& Cummings, E. M. (1994). Marital conflict and child adjustment: An emotional security hypothesis. Psychological Bulletin, 116, 387-411.

Davis, B. T., Hops, H., Alpert, A., \& Sheeber, L. (1998). Child responses to parental conflict and their effect on adjustment: A study of triadic relations. Journal of Family Psychology, 12, 163177.

Dodge, K. A., Bates, J. E., \& Pettit, G. S. (1990, December 21). Mechanisms in the cycle of violence. Science, 250, 1678-1683.

Fincham, F. D. (1994). Cognition in marriage: Current status and future challenges. Applied and Preventive Psychology: Current Scientific Perspectives, 3, 185-198.

Fincham, F. D. (1998). Child development and marital relations. Child Development, 69, 543-574.

Fincham, F. D., Beach, S. R. H., \& Nelson, G. (1987). Attribution processes in distressed and nondistressed couples: 3. Causal and responsibility attributions for spouse behavior. Cognitive Therapy and Research, 11, 71-86.

Fincham, F. D., \& Bradbury, T. N. (1991). Cognition in marriage: A program of research on attributions. Advances in Personal Relationships, 2, 159-203.

Fincham, F. D., \& Bradbury, T. N. (1992). Assessing attributions in marriage: The Relationship Attribution Measure. Journal of Personality and Social Psychology, 62, 457-468.

Fincham, F. D., Bradbury, T. N., Arias, I., Byrne, C. A., \& Karney, B. R. (1997). Marital violence, marital distress and attributions. Journal of Family Psychology, 11, 367-372.

Fincham, F. D., \& Cain, K. M. (1986). Learned helplessness in humans: A developmental analysis. Developmental Review, 6, 301-333.

Fincham, F. D., \& Jaspars, J. M. (1980). Attribution of responsibility: From man the scientist to man as lawyer. In L. Berkowitz (Ed.) Advances in experimental social psychology (Vol 13, pp. 81-138). New York: Academic Press.

Gladstone, T. R. G., \& Kaslow, N. J. (1995). Depression and attributions in children and adolescents: A meta-analytic review. Joumal of Abnormal Child Psychology, 23, 597-606.

Gottman, J. M. (1994). What predicts divorce? Hillsdale, NJ: Erlbaum.

Grace, N. C., Kelley, M. L., \& McCain, A. P. (1993). Attribution processes in mother-adolescent conflict. Joumal of Abnormal Child Psychology, 21, 199209.

Grych, J. H., \& Fincham, F. D. (1990). Marital conflict and children's adjustment: $A$ cognitivecontextual framework. Psychological Bulletin, 108, 267-290. 
Grych, J. H., Seid, M., \& Fincham, F. D. (1992). Assessing marital conflict from the child's perspective: The Children's Perception of Interparental Conflict Scale. Child Development, 63, 558-572.

Heider, F. (1958). The psychology of interpersonal relations. New York: Wiley.

Joiner, T. E., \& Wagner, K. D. (1995). Attributional style and depression in children and adolescents: $\mathrm{A}$ meta-analytic review. Clinical Psychology Review, 15, 777-798.

Kaslow, N. J., Deering, C. G., \& Racusin, G. R. (1994). Depressed children and their families. Clinical Psychology Review, 14, 39-59.

Kaslow, N. J., \& Nolen-Hoeksema, S. (1991). Children's Attributional Style QuestionnaireRevised. Unpublished manuscript, Emory University, Atlanta.

Kurdek, L. A. (1994). Areas of conflict for gay, lesbian, and heterosexual couples: What couples argue about influences relationship satisfaction. Journal of Marriage and the Family, 56, 923-934.

Kurdek, L. A., \& Berg, B. (1987). Children's Beliefs About Parental Divorce Scale: Psychometric characteristics and concurrent validity. Journal of Consulting and Clinical Psychology, 55, 712-718.

Mazur, E., Wolchik, S. A., \& Sandler, I. N. (1992). Negative cognitive errors and positive illusions for negative divorce events: Predictors of children's psychological adjustment. Journal of Abnormal Child Psychology, 20, 523-542.

Miller, S. A. (1995). Parents' attributions for their childrens' behavior. Child Development, 66, 15571584.

Noller, P. (1994). Relationships with parents in adolescence: Process and outcome. In R. Montemayor, G. R. Adams, \& T. P. Gullotta (Eds.), Personal relationships during adolescence (pp. 37-77). London: Sage.
Nunally, J. C., \& Bernstein, I. H. (1994). Psychometric theory (3rd ed.). New York: McGraw-Hill.

Osborne, L. N., \& Fincham, F. D. (1996). Marital conflict, parent-child relations, and child adjustment: Does gender matter? Merrill-Palmer Quarterly, 42, 48-75.

Phares, V., \& Compas, B. E. (1992). The role of fathers in child and adolescent psychopathology: Make room for daddy. Psychological Bulletin, 111, 387-412.

Radloff, L. S. (1977). The CES-D Scale: A self-report depression scale for research in the general population. Applied Psychological Measunement and Research, 1, 385-401.

Russell, A., \& Saebel, J. (1997). Mother-son, mother-daughter, father-son, and father-daughter: Are they distinct relationships? Developmental Review, 17, 111-147.

Seligman, M. E. P., Peterson, C., Kaslow, N. J., Tanenbaum, R. L., Alloy, L. B., \& Abramson, L. Y. (1984). Attribution style and depressive symptoms among children. Journal of Abnormal Psychology, 93, 235-238.

Shaver, K. G. (1985). The attribution of blame: Causality, responsibility, and blameworthiness. New York: Springer-Verlag.

Turner, J. E., \& Cole, D. A. (1994). Developmental differences in cognitive diatheses for child depression. Joumal of Abnormal Child Psychology, 22, 15-32.

Weiner, B. (1985). 'Spontaneous' causal thinking. Psychological Bulletin, 97, 74-84.

Received September 22, 1997

Revision received July 15, 1998

Accepted July 22, 1998 